Presented at the Pacific Coast Meeting of the American Institute of Electrical Engineers, Spokane, Wash., September 10, 1914.

Copyright 1914. By A. I. E. E.

\title{
A DISTRIBUTION SYSTEM FOR POWER PURPOSES
}

\author{
BY F. D. NIMS
}

\section{Abstract of Paper}

The paper describes the distribution system of the Western Canada Power Company, Limited, touching on the overhead and underground systems in general. It describes the advantages obtained by duplicating lines, both for eliminating outages and from a financial standpoint. Mention is made of the advantages obtained by using a steel-taped lead-armored cable placed directly in the ground, figures showing the exact cost of such an installation being given.

IN laying out a distribution system for power purposes primarily, instead of a lighting or combined power and lighting load, several differences are encountered which lead to a much simpler and less expensive system. It is my purpose to describe the system of the Western Canada Power Company, Ltd., of Vancouver, B.C., giving some of these points in detail.

This company has its power house at Stave Falls, B.C., about 35 miles $(56.3 \mathrm{~km}$.) east of Vancouver, distributing power to Vancouver and the surrounding districts. The power house is located nearly in the center of a somewhat sparsely settled district containing several fairly large industries scattered throughout it at a maximum distance of 18 miles $(28.9 \mathrm{~km}$.) from the power house. A line leads south to the international boundary at Sumas, Wash., where it feeds a line of the Puget Sound Traction, Light and Power Company, of Bellingham, Wash., supplying $5000 \mathrm{kw}$. at 60,000 volts. This line is wood pole construction, single circuit, with pin type insulators, the conductor being a No. 0 equivalent steel core aluminum cable. The average span is $250 \mathrm{ft}$. $(76.2 \mathrm{~m}$.) and the maximum $970 \mathrm{ft}$. $(295.6 \mathrm{~m}$.) Arm pins are of the saddle type, made of one-in. $(2.54-\mathrm{cm}$.) galvanized channel iron, no bolts going through the arm. The two legs of the pin are bolted together just above and below the arm. On angles, a small lag is screwed into the arm as a heel. This type of construction is shown in Fig. 1.

A steel-tower line, carrying two circuits of No. 0 hard-drawn 
stranded copper with hemp center, runs from the power house for 33 miles $(53.1 \mathrm{~km}$.) to the receiving station at Ardley, located half way between the cities of Vancouver and New Westminster, and practically at the center of gravity of the industrial load. At Ardley, power at 60,000 volts is delivered to the British Columbia Electric Railway Company, Limited, which takes the current into Vancouver, where it parallels with that company's own system. Ardley station also steps the voltage from 60,000 down to 12,000 , at which it is distributed to Vancouver, New Westminster and the surrounding district. The standard steel tower is shown in Fig. 2. On account of difficulty encountered from sleet and snow during the winter of 1912-13, the middle arm was extended, and Fig. 3 is a view of the same tower as it stands today.

All 12,000-volt lines are on wooden pole construction and carry, as far as possible, only one circuit to the pole, it being our belief that better service can be provided through making each circuit loop back to the transforming station by an entirely different route than to duplicate circuits on a single pole line; where more than one circuit is on a pole line they are generally considered and operated as a single unit. This method, by proper sectionalizing of the lines, reduces the chance of outage to a minimum, and when work is being done on the line, or stumps are being blasted, a short section can be isolated and killed so that linemen are absolutely protected from adjacent circuits; or if a piece of stump.is blown into the line, no short circuit is occasioned which burns off the conductors.

Aside from the power house and main receiving station, no substations are used, as there are no voltage regulators or similar apparatus which require attention. Transformers are generally placed on pole racks and operate as ordinary distribution transformers. Figs. 4 and 5 give a typical example of such a rack. It carries three $50-\mathrm{kw}$. transformers stepping from 12,000 to 2300 volts. Switches are either oil-break, pole type, or a combination fuse and disconnecting switch mounted on the pole. The company has designed and builds in its shop such a switch, which answers the purpose exceedingly well and costs very little.

Patrolmen are stationed at important switching points so that these switches may be operated quickly in case- of emergency. Fig. 6 shows an installation of three $333-\mathrm{kw} .12,000-$ to 2300-volt water-cooled transformers in the outskirts of the city of Vancouver. These transformers are indoor type so that 
PLATE LXXXIX.

A. I. E. E.

VOL. XXXIII, 1914

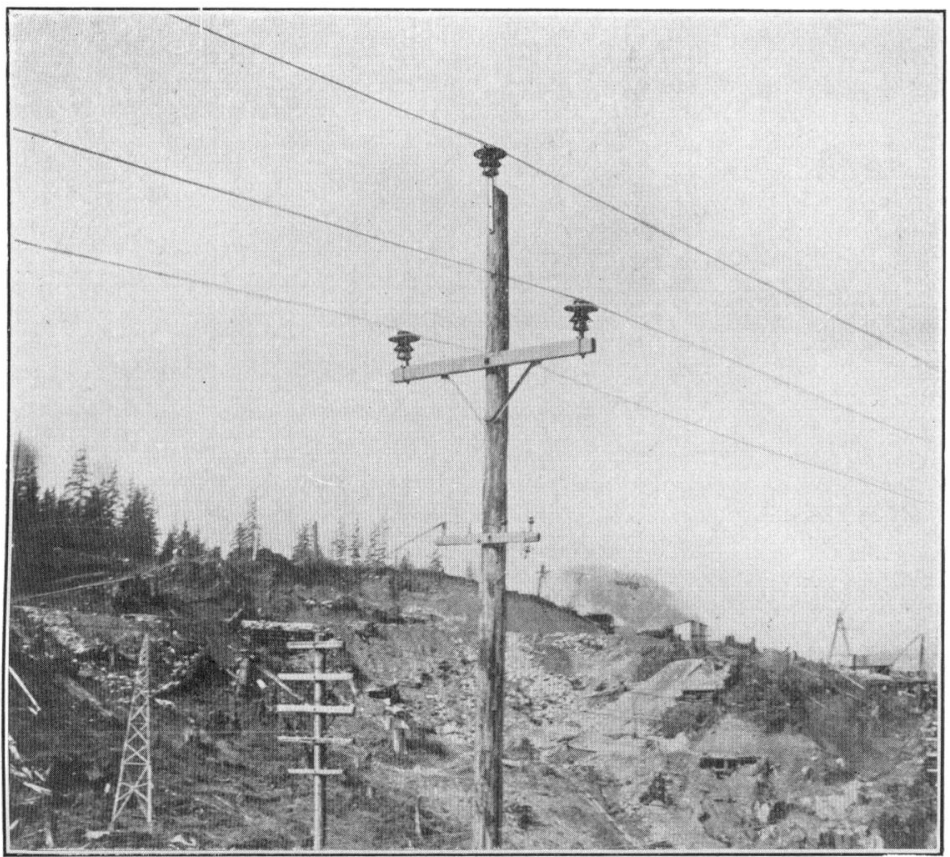

[NIMS]

Fig. 1-Pole on Bellingham 60,000-Volt Line, Showing Saddle TyPe ARM PIN

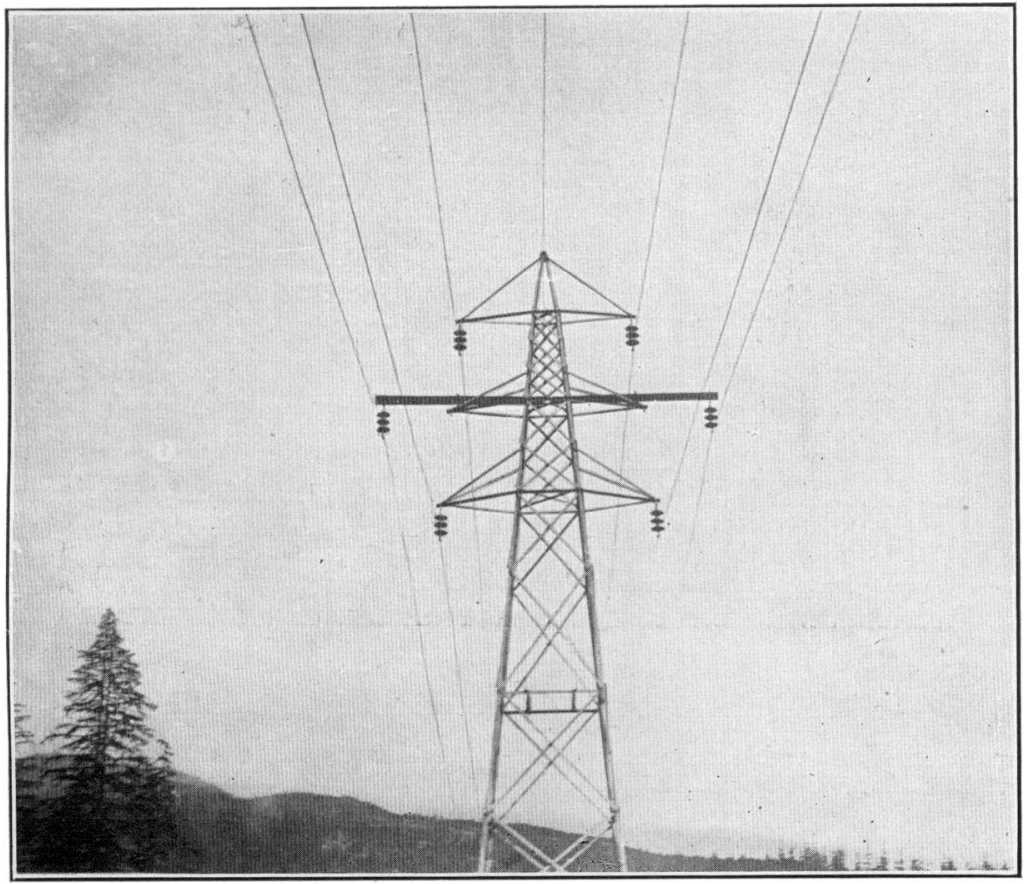

Fig. 3-Standard Steel Tower with Center Arm Extended 
PLATE XC.

$A$, I. E, E.

VOL. XXXIII, 1914

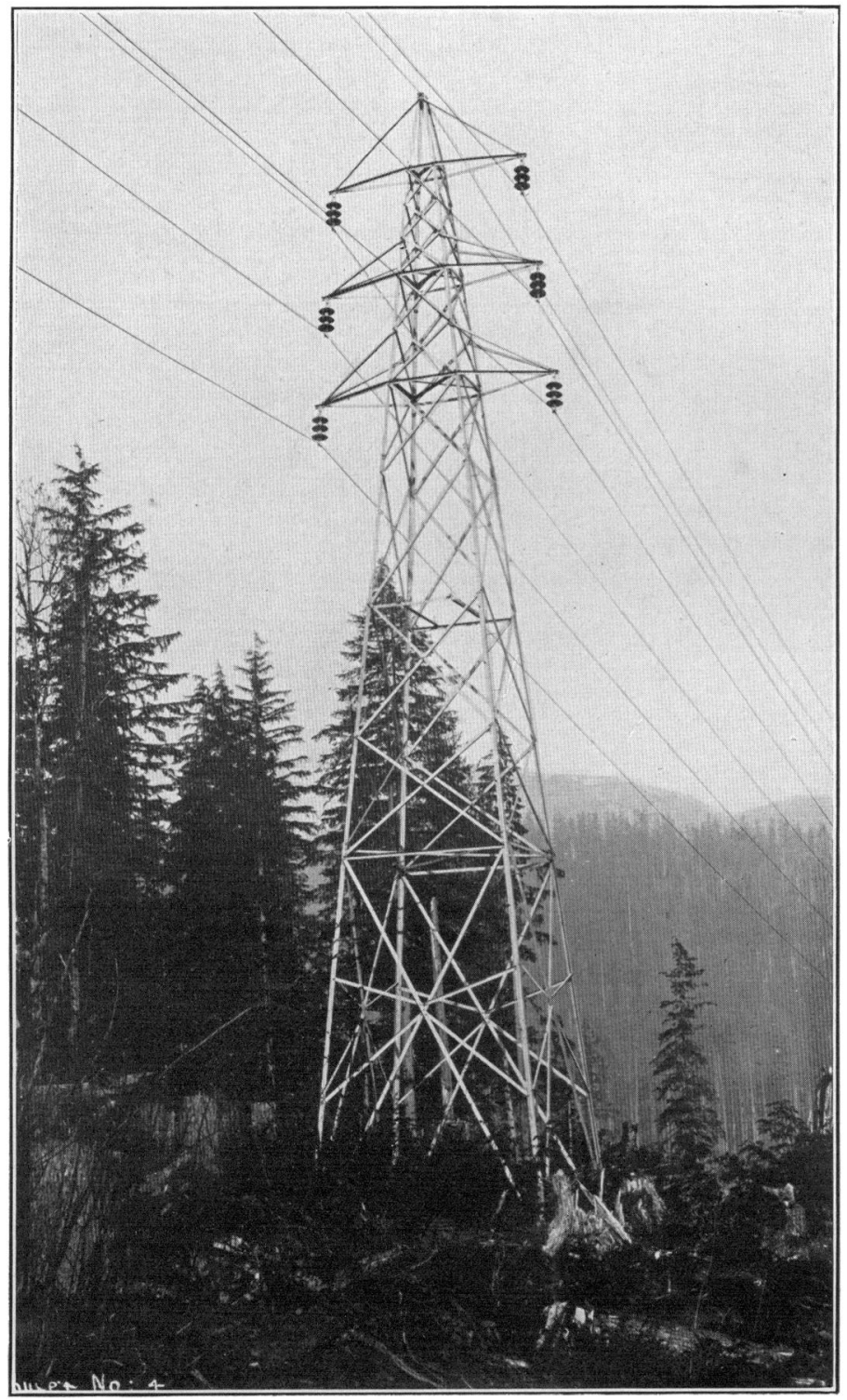

Fig. 2-Standard Steel Tower with Ground Wire on Apex 
A. I. E, E.

VOL. $X X X I I I, 1914$

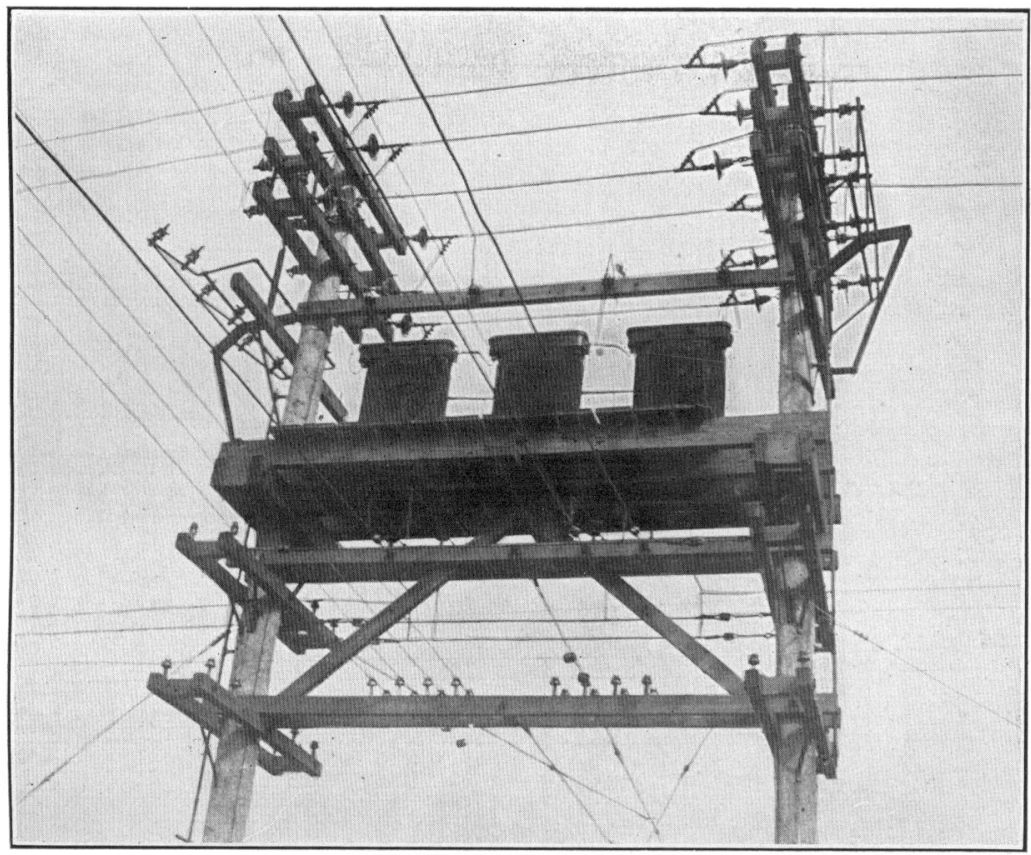

[NIMS]

Fig. 4-Open Air Rack Carrying Three 50-kw. Transformers, $12,000-2300$ Volts. Operated with Pole-Top Switches

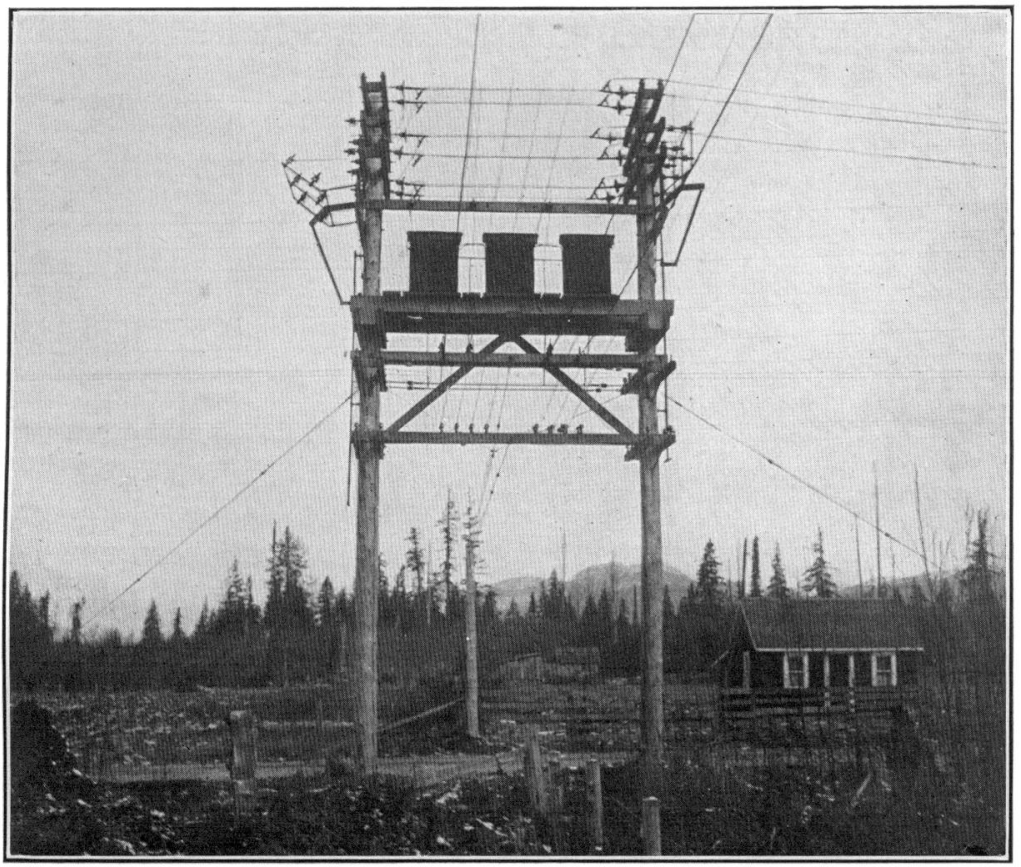

Fig. 5-Another View of Same Rack 
PLATE XCII.

A. I, E, E,

VOL. XXXIII, 1914

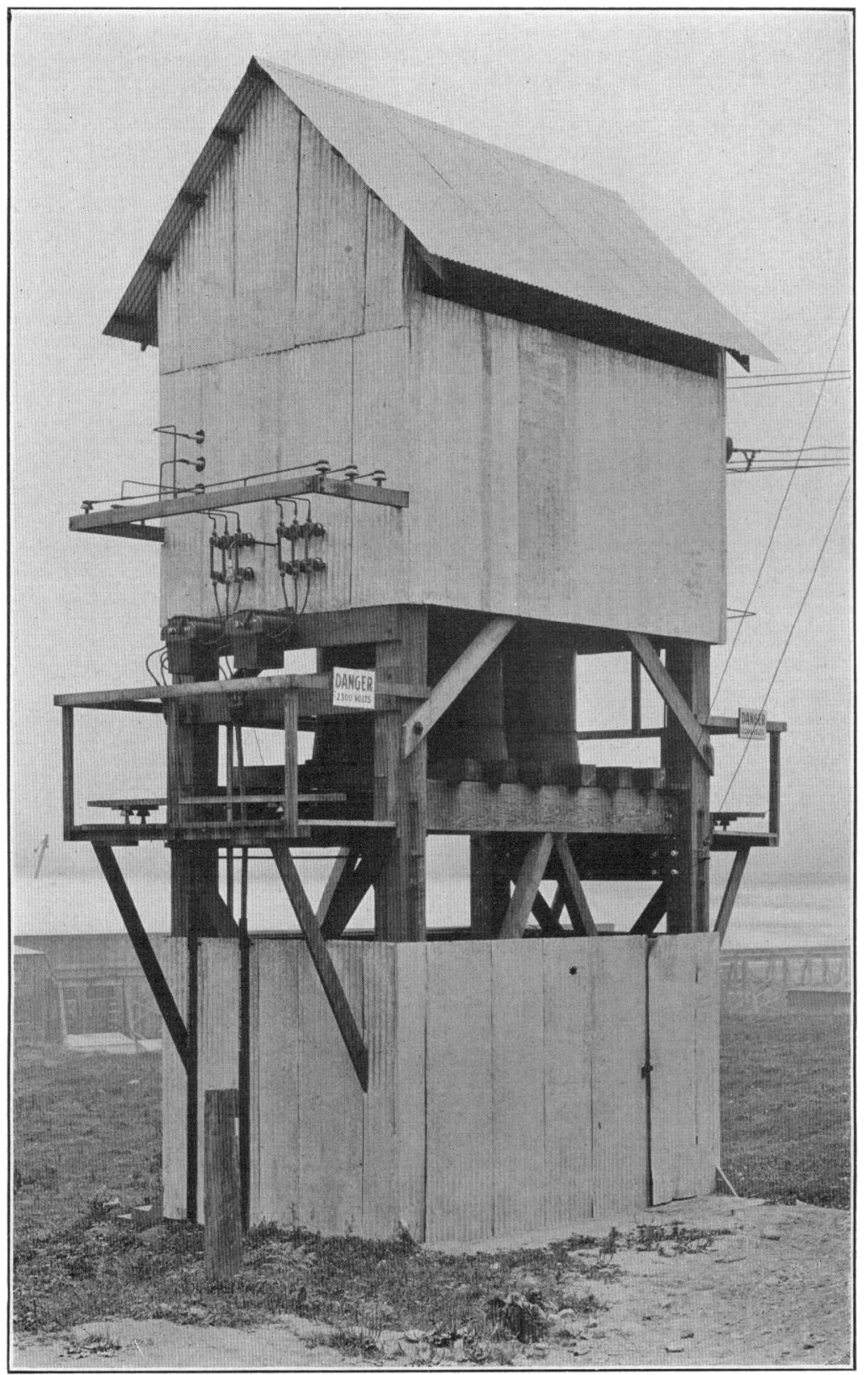

[NIMS]

Fig. 6-Rack Carrying Three 333-kw., 12,000-2300-Volt WaterCOOLED INDOOR TYPE TransFormers 
PLATE XCIII.

A. I. E. E.

VOL. $X X X I I I, 1914$

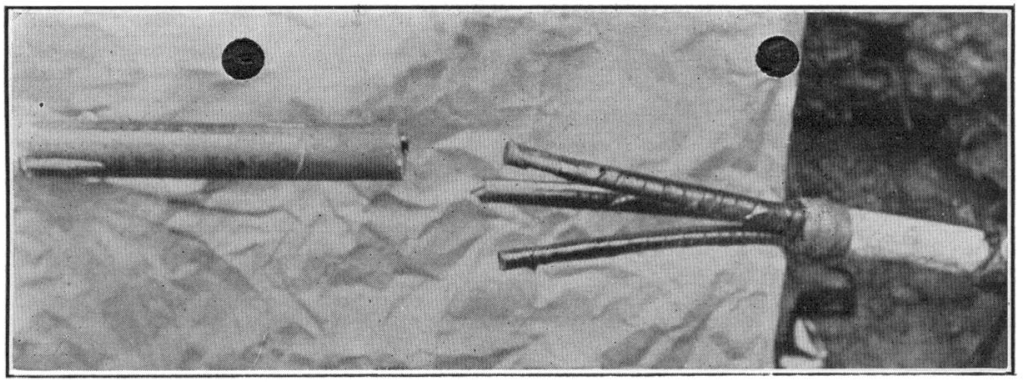

[NIMS]

Fig. 7 -Cables Showing One End Ready for Joint

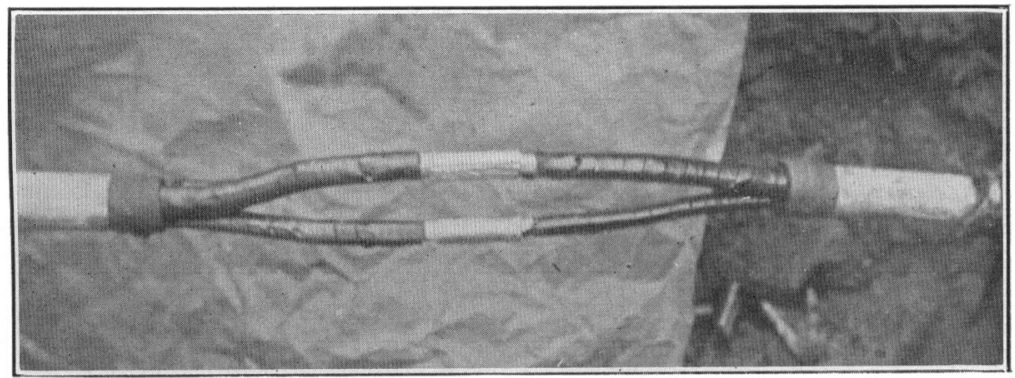

Fig. 7A-Joints with Connectors Soldered

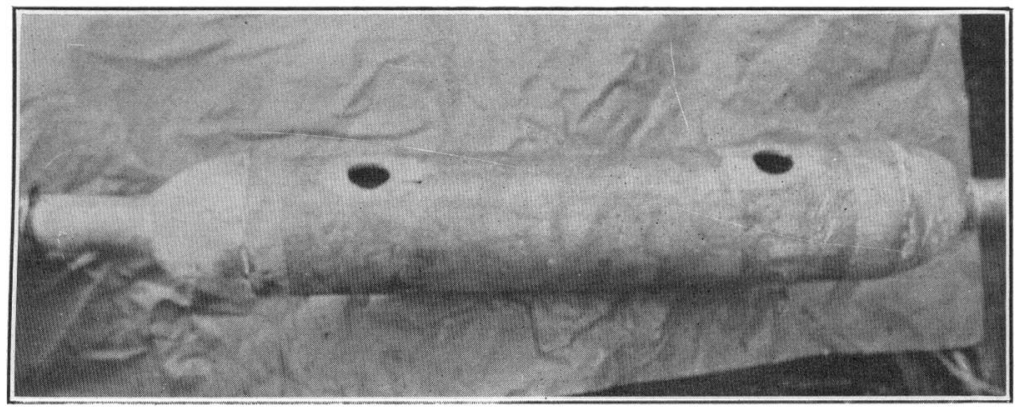

[NIMS]

Fig. 7b-Joint with One End Wiped to Lead Sheath of Cable 
PLATE XCIV.

A. I. E. E.

VOL. $X X X I I I, 1914$

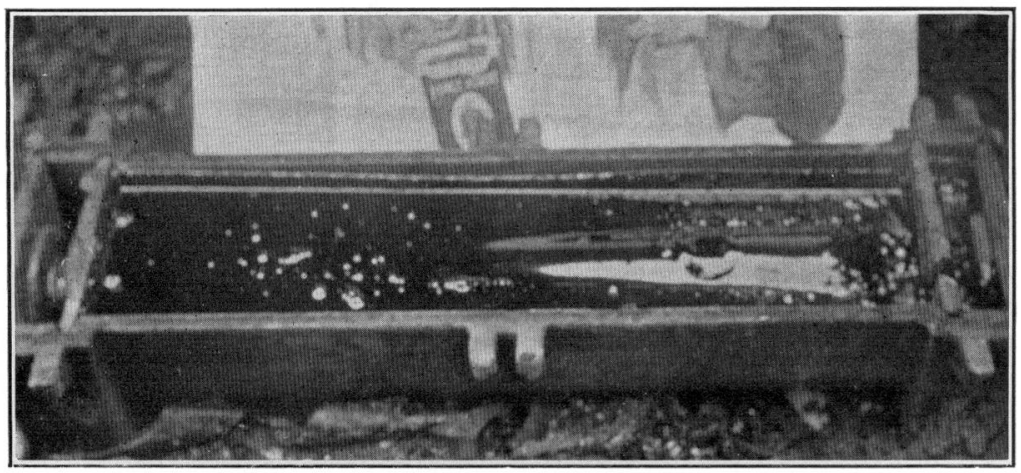

[NIMS]

Fig. 7C-Straight Joint Box, Partly Filled with Bitumen, Ready FOR COVER

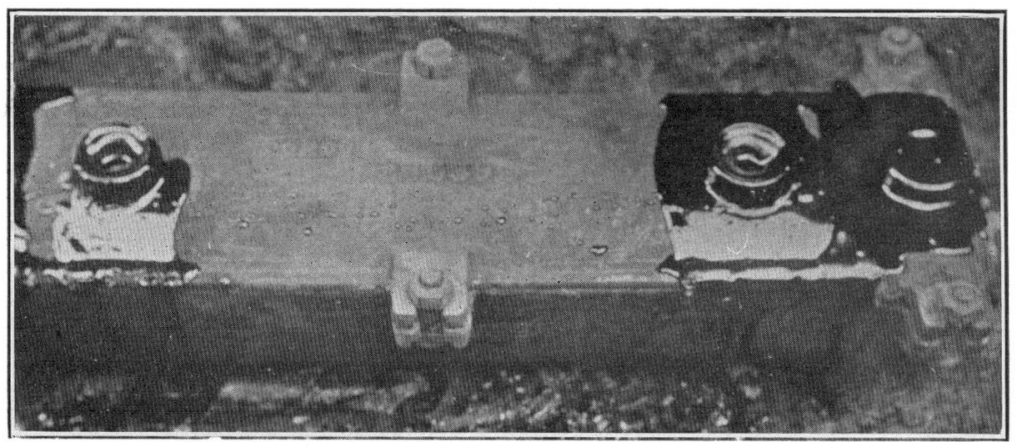

Fig. 7D-Joint Completed

[NIMS]

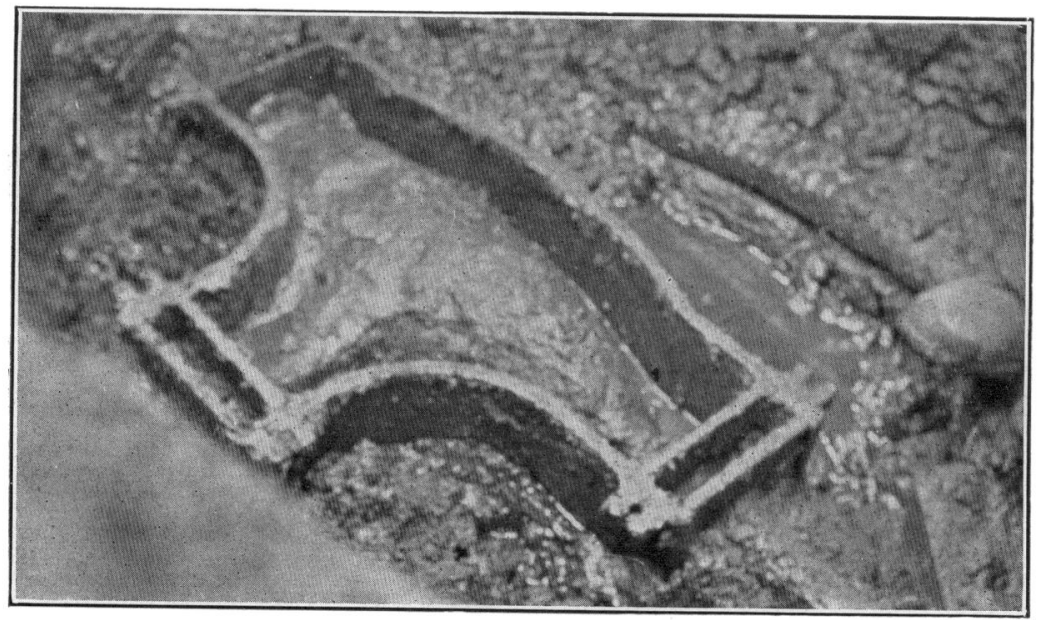

Fig. 8-Tee Joint Half Full of Bitumen 
PLATE XCV.

A. :. E. E.

VOL. XXXIII, 1914

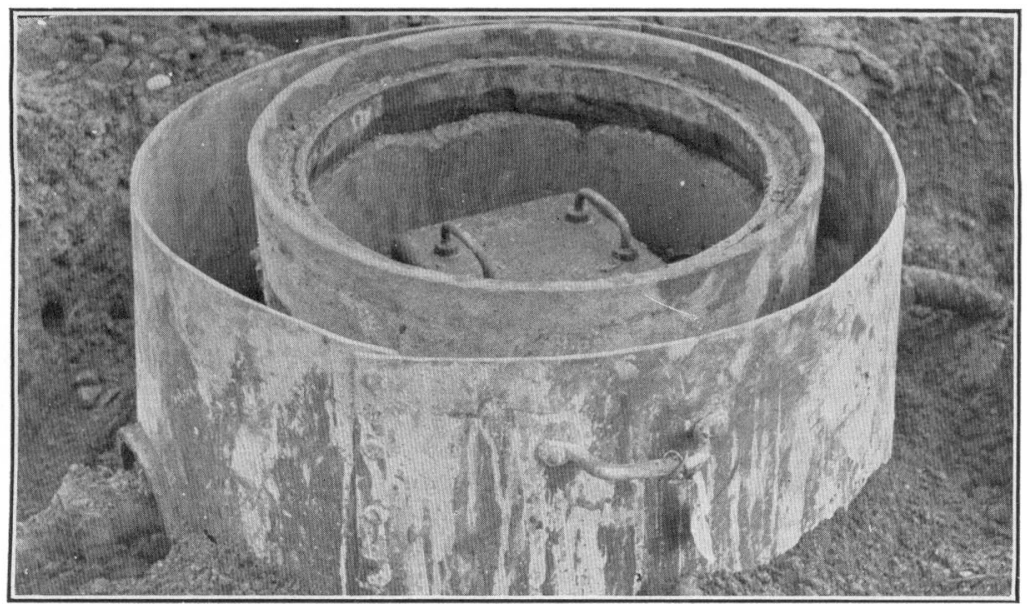

[NIMS]

Fig. 9-Section Box in Place and Outer Form Ready for Pouring CONCRETE

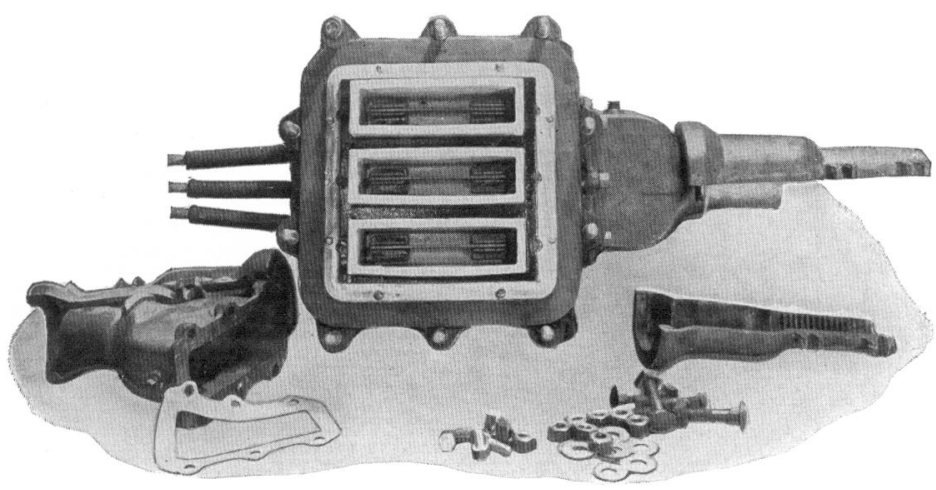

[NIMs]

Fig. 10-Section Box Showing Porcelain Compartments and COPPER LINis 
it was necessary to roof them over with galvanized sheeting. Water for cooling is taken from the city mains. The view is from the 2300-volt side, showing the disconnecting switches, outdoor type oil switches, cable terminals and cables with their pipe protection. A patrolman, who lives in the vicinity, visits the station periodically and adjusts the flow of water through the cooling coils. In some cases, where a mill or factory has sufficient electrical apparatus of its own to warrant the employment of a skilled electrician, water-cooled transformers are installed in a small galvanized iron building. In short, the entire 12,000 -volt system is handled in the same manner as a 2300 -volt system, except that a circuit must be killed for a man to work on it.

Distribution in the cities of Vancouver and New Westminster is at 2300 volts by means of steel-taped and lead-armored cables laid directly in the ground, without conduit or other protection, except where crossing railway tracks or busy streets, where wood duct is laid to facilitate the pulling out or replacing of a cable without interruption to traffic. A trench is dug $30 \mathrm{in.}$ $(76.2 \mathrm{~cm}$.) in depth, and of a width corresponding to the number of cables to be laid, (cables in place are from 4 to 6 in. -10 to $15 \mathrm{~cm}$.-apart) the cable is reeled out and dropped directly into the trench. Joints are made by joint boxes, which cover the same character of joint that is made in the ordinary leadcovered cable, the space between the lead and the box being filled with ordinary bitumen, the box serving as a protection to the lead and also clamping the steel armor on both sides of the joint, providing electrical conductivity in the steel as well as mechanical strength in the cable as a whole. Fig. 7 shows five views of making a straight joint; the first showing the cable with one end ready for the joint, the armor having been stripped back, the lead cut back and the conductors separated. Fig. 7A shows the joint as made with copper sleeve connectors. Fig. $7_{\mathrm{B}}$ shows the joint with one end wiped to the lead sheath of the cable. Specially refined bitumen is poured through the holes in the lead sleeve after the ends are wiped, and the holes then capped with lead. Fig. 7c shows the straight joint box, itself, with the cover off, half full of bitumen, and Fig. 7D the completed joint. Fig. 8 shows the lower half of the joint box in the trench. Taps are made in a similar manner by means of a three-way box. At frequent intervals section boxes are placed in the line, these boxes being $18 \mathrm{in}$. $(45.6 \mathrm{~cm}$.) below ground level in a small manhole, or, more properly, handhole. 
These holes have, as a bottom, a pad of concrete on which the box rests, the walls being circular and of cast iron; the entire hole being 26 in. $(65 \mathrm{~cm}$.) in diameter. The walls are flanged to take an ordinary cast manhole plate, which is used as a covering, these being flush with the street. Fig. 9 is a section box and hand hole with the steel form around it ready for pouring concrete. After pouring, the form is slipped off and the earth tamped in up to the concrete. The box has a bolted top which can easily be removed, and the copper links, which are set in porcelain compartments, can be taken out by means of wooden tongs. These boxes are used to isolate sections of cable when necessary to make new taps or work on the live conductors in any way, and also as interconnecting links between various cables, giving as a result several rings or loops. Fig. 10 shows a view of one of these boxes before placing in the handhole. The bolted cover is removed, showing the porcelain compartments and the copper links. The bell is of brass with a lead sleeve wiped in which fits over the lead sheath of the cable and is then wiped to it. After the conductors are connected and the lead joint wiped the bell is filled with refined bitumen, through the plug holes left for that purpose. The split armor clamp is also shown on the right side of the box.

Distribution transformers are placed either in vaults on the customers' premises or on poles, in which case the cable is carried to the top of the pole, where it terminates in an outdoor type terminal. Secondaries may be carried either back down the pole in the same kind of cable or run overhead to the building. Where cables run up the poles an additional protection is given by means of an iron pipe through which the cable runs. This pipe extends to a point about ten feet above the ground.

The question of cost on such an underground system must be taken up in each individual case, for it will vary a great deal with the quality of soil, cost of labor, probabilities of taps, extensions, etc., but it may be said, in general, that in places where it is not required to lay more than four cables in a trench, the steel tape cable, laid directly in the ground, will be found to be cheaper than any of the other systems. As a typical example of actual costs the following gives an idea, the figures being taken from a job carried out in Vancouver during 1911-1912. 


\begin{tabular}{lllr} 
Size of Cable & Amount laid, feet & Cost per ft., cents & Total cost \\
No. 00 & $73,336.6$ & 52.24 to 62.18 & $\$ 44,319.26$ \\
2 & 560.0 & 42.5 & 238.00 \\
6 & $1,071.3$ & 29.6 & 317.10 \\
\hline TOTALS & $74,964.9$ & 60 cents average & $\$ 44,874.36$
\end{tabular}

Pulling cable (including splicing straight joints) $\$ 0.04$ per $\mathrm{ft} \ldots \ldots \ldots \ldots \ldots \ldots 2,962.69$ Trenching

Unimproved streets

Macadamized

Plank walk

Concrete walk

Wood block (con. base)

Brick Do.

Stone Do.

Bitulithic pavement

TOTALS

74 straight joint boxes

15 Tees

4 Outdoor terminals

2 Inside terminals

8 End bells

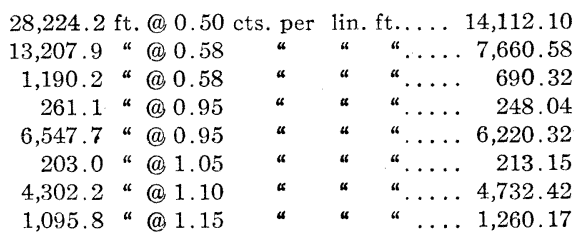

$55,022.1 \quad 0.632$ average

$35,137.10$

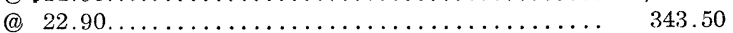

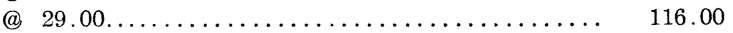

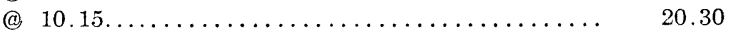

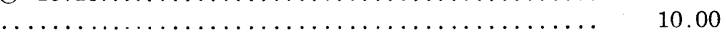

409.04

235.08

$3,877.43$

439.49

294.70

$2,250.00$

$\$ 92,102.29$

TOTAL COST

Cost per ft. of cable $\$ 1.23$

Cost per mile of cable $\$ 6483.84$

Feet of cable per ft. of trench 1.36

No overhead charges or engineering are included in the above.

Operating troubles have been few and far between, there having been, during two years' operation, but three cases. Two of these were caused by city workmen making sewer excavations taking the cable for the root of a stump and chopping into it with an axe or pick. On one of the pieces of cable so damaged we found the marks of 13 blows before the axe cut through to the conductor. The third case was a faulty joint at a section box which broke down the day after it was placed in service.

A complete card system is kept containing records of all cable locations, joints, etc., and we installed our own hubs in the streets as markers, the city hubs not being well defined.

This cable is practically a submarine cable, and in fact we have one length of $1500 \mathrm{ft}$. $(457 \mathrm{~m}$.) crossing the Pitt River, which has now been in service for two years without any trouble. The bottom on which it lies is fine silt or sand and there is a four-mile current caused by the tide. In another case it was necessary to cross a railway yard to furnish power to a pump located about $1000 \mathrm{ft}$. $(304 \mathrm{~m}$.) from the factory of the consumer, 
the motor driving the pump to be controlled from the factory. As the expense of excavating for the laying of a cable would have been excessive and there was already a 12 -in. (30.4-cm.) water main running from the pump to the factory, the cable was pulled in the pipe, the inlet and outlet of the cable being made through stuffing boxes. This has also proved very satisfactory.

The cable is composed of stranded conductors insulated with paper, the three conductors being insulated again with paper as a unit before the lead is put on. In most of the cable in this installation the conductors are sector-shaped, so that there are no spaces to be filled with jute or other material and a smaller over-all diameter is obtained, for a given size, than is possible with the round conductor, thus requiring less lead, steel and jute, and making a cable lighter in weight. The lead sheath is $\frac{1}{8}$ in. (3.1 mm.) thick and over this is wound jute yarn impregnated with tar. Outside of this jute are wound, in the same direction, two layers of mild steel tape $0.039 \mathrm{in.}(1 \mathrm{~mm}$.) in thickness and $1.5 \mathrm{in}$. (37 mm.) in width, so laid as to break joints. Over this tape is again wound yarn impregnated with tar. The over-all diameter of such a cable in three-core No. 00 for 4000 working voltage is about $1.75 \mathrm{in}$. (34.5 mm.).

One of the most important factors in the use of a cable buried directly in the ground, instead of being in conduit, is the ease with which heat can be radiated. Although the amount will vary somewhat with the character of the soil, it is safe to say that on this account an increase of approximately 15 per cent may be allowed in the current-carrying capacity over that in conduit. Exhaustive tests on this subject are now being carried out.

In regard to the life of a cable installation of this sort, nothing definite can be said as yet. The writer has personal knowledge of a large installation which has been in service in volcanic soil in the City of Mexico since 1900, and no perceptible deterioration has occurred, except where exposed to extreme electrolytic action, and in these cases it had a much longer life than lead cable in conduit in the same vicinity, due to the steel tape acting as a protection. 


\section{Discussion on "A Distribution System for Power Pur- poses" (Nims), Spokane, Wash., September 10, 1914.}

J. B. Fisken: It was my good fortune last year at the Pacific Coast Convention at Vancouver to see quite a good deal of the work that Mr. Nims had done with this ductless cable. I have noted some of the points on which I would like to hear some discussion. These are: the relative cost of ductless and duct lines, the use of the various insulations, such as paper, varnished cambric, and rubber, and the relative advantages of the wire of the shape he mentions as against round wire.

It appears to me that this system of ductless underground cable is eminently suitable for distribution in residential districts, but I don't see how it can be practicable in congested districts such as the business part of the various cities where you might have as many as thirty or forty cables in one duct line; it would appear to me that there would be many operating difficultiesor, rather, maintenance difficulties in keeping such a lay-out as that in commission.

P. M. Lincoln: This matter of the kind of cables that Mr. Nims is using is probably the most interesting point in the paper.

I ask first if he has any difficulty in locating faults and if he can locate them so that he does not have to dig very much when he comes to find the fault and repair it; also I presume that this type of installation would not be at all applicable where you have to take up pavement to make repairs - in that case I presume it would be out of the question.

The question which Mr. Nims mentioned, of this being much more capable of getting rid of heat, is an important one. When the Niagara Falls plant was installed 2200 volts was the voltage and it was considered high at that time-1893-4;-those were $3740-\mathrm{kv}-\mathrm{a}$. generators, and there were ten of them, which gave a whole lot of current to take care of. That current was distributed to our various customers at 2200 volts and it was distributed through cables in ducts, and the problem of getting rid of the heat in those ducts was at that time and still is one of the most difficult problems which has to be dealt with. I can assure you that any means of increasing the capacity of the cable, so far as the heat is concerned, appeals to me on account of my experience there. We made many duct conduits in the early days, some of them as many as 36 ducts, and we found the cables in the middle of those many-duct lines would have an exterior temperature rise of 50,60 or $70 \mathrm{deg}$. fahr. to begin with, some of them more than that, so that you can see that the problem of getting rid of the heat, particularly the heat in those conductors which ran in the interior ducts of the conduit, became a very serious one. They have even gone so far as to circulate water in some of the ducts in order to get rid of the heat. This is really an important problem, particularly where large amounts of power have to be dealt with at relatively low voltages.

F. L. Rohrbach: Regarding the cost of underground systems 
which would include a duct and manholes, I do not think there is any question but what Mr. Nims has used the cheapest method in his system at Vancouver; but I ask Mr. Nims if he has considered the case of using ducts and leaving out manholes (except those necessary for switching); also the use of lead-covered cables, and what that would mean. I suppose this cable could be exposed at points where the manhole would naturally be built, so that in case of trouble it will only mean digging down at each manhole, or where the manhole should be, and pulling out the cable that is in trouble. It would mean also that you could watch the size of your cable; and when necessary it would be easier to take out a small cable and replace it with a larger one. Now, I do not know exactly the difference in cost between this steel-armored cable and lead-covered cable, but judge it would be about ten cents per foot, that is, for the same size cable used with the steel armor and cable used in duct. Where you have three ducts in one line, they can be laid cheaper than three lines of single duct-I would figure the saving in cable roughly at ten cents a foot; thus lead-covered cable would be probably $\$ 7,300$ cheaper. Another place you could save would be in the cost of the straightjoint boxes; that would be $\$ 1100$ over the other method, as I understand these boxes are a means of connecting the armor on each side of the lead sleeve and keeping it continuous.

I do not understand the items under the " six railway crossings " and " ninety-six street crossings." There are no lengths given and I have no idea what the total distance is. If they are ordinary streets of 75 or $100 \mathrm{ft}$. it seems to me the cost is high, as I understand that is where the wooden duct was installed. Of course I know nothing about the labor costs in Vancouver, but here in Spokane I would estimate that a single fiber duct surrounded with concrete could be installed for about sixteen cents per duct foot, and wooden ducts for twelve or thirteen cents. Of course my idea in installing this lead-covered cable, in a duct throughout the whole system, as well as at crossings, is simply for the purpose of being ready to pull out in case of trouble; and I think Mr. Nims will find that if there is a breakdown in the cable there will be some difficulty in locating the point of trouble. I have found that a good many Eastern companies in testing for trouble use what they call the "cutand-try" method. That does away with any complex test. Most of them simply go out and cut the cable probably at the center and find out which half it is in and then trace it back. I think this would probably be the case at Vancouver, although there may be some other method of doing it. There is one method which is used by simply putting a current on the conductor that is in trouble and then reversing the current. You go along in each manhole with a compass held close to the cable, and when you come to the point where your compass does not vary, you have passed the point of trouble and you know which section it is in; but you would be unable to do that with armored cable. 
I suppose that Mr. Nims has certainly considered the conduit and manhole construction, and if he has I would like to hear approximately what the difference was in his estimates, and also if he has considered the duct alone, leaving out the manhole, because it would be a simple question to leave a four-foot section and have your joints there so that you could easily get down and uncover your cable. Of course I understand that by doing this you would have to cut your cable up in smaller pieces, have more joints, but you would get rid of making your additional joints over your lead-covered cable which you do with these straight joints. I think that here in Spokane I could come pretty close to this total cost, and put in a single duct, leaving out the manhole.

There is another question: Mr. Fisken said something about a large number of cables. I think it would be entirely out of the question to put in many cables; in fact, I do not know but what four would be too many, and especially as the size of the cable is not stated; for it would depend entirely upon the size of the cable. When you get a cable from about 1.2 inch to 1.7 inch the additional cost of the armor runs up considerably, varying from ten cents if the lead sheath is 1.2 inches in diameter, up to 19 or 20 cents, going up very rapidly to 1.7 . The cost of the duct in fiber (fiber and cement) is about 16 cents; that is not including the trenching because I have taken for this estimate that the trenching, is already done; I have only taken the cost of installing the duct, which will run from probably 16 cents down to 10 cents, depending on the number of ducts. A wooden duct would be cheaper, possibly from fourteen down to seven or eight cents.

The amount of heat dissipated by this cable is placed approximately at 15 per cent over one working in a conduit. I would like to ask Mr. Nims if he has made this test, whether it is between armored cable in a duct and armored cable in the ground, or whether it is between armored cable in the ground and leadcovered in the duct. The additional insulating (jute) over the armored cable would probably cause an increase in heat of seven or eight per cent; that is, it would be harder to get rid of the heat due to the doubling, practically, of the insulation.

And regarding electrolysis, there is no question that the armor would be some protection against electrolysis, but still if electrolysis was present the armor might give way and the lead would possibly be eaten up, or if electrolysis was not sufficient to eat away the armor it probably would not injure the lead so quickly.

C. S. MacCalla: I had a little indirect experience some years ago in the system which was in the city of Sydney, Australia. The New South Wales government owns and operates the street railways in Sydney, which is a city of about three-quarters of a million; I happened at that time to be working for an American contractor who was installing a three-phase generating 
apparatus and substations. The cable was placed by an English contractor; it differed from Mr. Nims's cable and was considerably inferior to it; it had no iron armor and no insulation outside other than a little bitumen. The cables were laid in open trenches, I think about as many as eight in a trench, and were surrounded with a bituminous material and covered with treated plank. This cable was installed some months before the generating apparatus was ready for operation, and when they came to put the current on we had all kinds of trouble; and when investigated it was found that electrolysis had destroyed a large portion of the cable. If I had been the operating man at that time I would have been very thankful for a few ducts to pull out the cable. The whole city, which was largely paved, had to be dug up, the streets were torn up for some time, and the system had to be practically relaid.

H. V. Carpenter: I have had a little experience along this line, and I might state one instance which shows the durability of the steel armor. We have one cable line across the college campus, in which the cable is laid about two feet underground; during the excavation for our new engineering building recently they got over the line too far, and I found them tugging away at the cable with a plow and team, but they hadn't damaged it, so we moved it over out of the way. The cable showed no injury at all. It seems to me that in cases of that sort, where it is in a park or some place where there is no pavement, and there is no danger of electrolysis or any of those things, the use of the buried cable is very satisfactory.

Regarding the location of faults, I would like to say that the system which is now in use quite commonly by water companies, for locating troubles in pipes, could be used for locating faults in this cable. That is, put a current through the cable to the point where the fault occurs, and then take a coil with a good many turns on it and connect up the telephone receiver, walk along the ground over the cable, find the fault and dig it up and fix it.

P. M. Lincoln: About that last-mentioned method of locating faults-I have had some experience with it. That very same scheme was tried by the Niagara Falls Power Company back in about 1896 or 1897 , and the trouble we found was that the location of the fault thereby was not definite. There would be at the point of the fault a slight diminution of sound in the telephone, but you would hear the telephone still buzzing for five hundred feet beyond the fault, and we found that the location of the fault was so indefinite that we had to abandon that scheme and locate our faults by some other method.

H. V. Carpenter: I think the accuracy with which that location could be made would depend considerably on whether het inductive coil was working by electrostatic action or by electromagnetic. If a current of sufficient strength is put through the cable to the point where the fault is located, so that 
the action is not electrostatic, then the trouble would be located quite accurately.

P. M. Lincoln: The influence of the cable upon the telephone is due to electromagnetic induction entirely, and the difficulty was undoubtedly due to the fact that the current, after it left the fault, followed the cable and got away into the ground rather gradually and the telephone would not distinguish whether the current flowed in the copper conductor or in the lead sheath.

Edward Woodbury: The paper states: "Water for cooling is taken from the city mains." I wonder if they waste that water or whether they attempt to save it. We have a small pump and cooling tower and the water is circulated; then for an emergency we have a city supply and in case the motor stops running the city water is turned on automatically.

G. B. Rosenblatt: Regarding water-cooled transformer substations, I wonder whether, where Mr. Nims comes from, they have any trouble with their cooling system from freezing. The matter of climatic conditions might be of further interest. I wonder how much freezing of the ground they have to contend with when they have any repair work to do in winter on the cable system.

John Harisberger: The use of cables in trenches without ducts appeals to me, especially as to first cost, if it is not intended to make numerous connections.

The problem of cooling water for transformers has confronted most operating companies. Use of city water is expensive, and a cooling tower is not a perfect arrangement. We have a rather novel arrangement in our Everett substation to prevent the waste of water. There are two pipe lines, one at 125 pounds pressure and one at 80 pounds pressure. The water for the transformer cooling coils is taken from the 125-pound line through a reducing valve which reduces the pressure to 90 pounds, and is discharged into the 80-pound line. This arrangement has proved quite satisfactory.

One of the gentlemen mentioned a cut-and-try method for locating trouble in cables. I wonder if Mr. Nims had any facilities for sectionalizing his 60,000-volt overhead lines, such as pole-top switches. If pole-top switches are used, has he found them satisfactory?

L. J. Corbett: This paper relates to the actual engineering features of an installation for a definite purpose. We can appreciate a difference between the installation for power alone, and one for both lighting and power. When the lines are opened temporarily or the voltage fluctuates due to some heavy load coming onto a system of the latter class, there may be a good deal of trouble caused, and complaints will be heard from the lighting customers. On a purely power load the fluctuations are not so noticeable, and while shut-downs may cause inconvenience, this is not comparable with a similar one on a lighting system, and for these reasons certain economies can be effected 
in the installation of such a system. Going still further, there are yet other systems which take greater liberties. In the case of a private manufacturing plant, for instance, which is generating or even buying its power and distributing it through its own system, liberties are sometimes taken with standard construction which would not be considered at all by a power company serving an exacting public. In Mr. Cotton's address which was given yesterday, we heard the term " near confiscation." We have in such cases as these at times a condition of " near unsafeness," and the limit is quite often approached rather closely.

I recently had occasion to make an estimate upon a system to use steel-armored cables, and found the cost to be somewhat more than that of lead cable and iron pipe conduit. The difference was not great, but it appeared to me to be in the wrong direction.

As has been brought out, quite frequently tests are made so closely that one can locate a fault within a very few feet, if the data regarding the length of line, distances, etc., are definitely known. In one or two of the cases just mentioned where the coil and telephone receiver were not successful, it occurs to me that possibly the reason for not locating the fault more closely might be this: If you have a large number of cables in a set of ducts, only one of which is faulty, your instrument will not be so sensitive as it would be in a case where there is but one cable, as in the campus system mentioned by Professor Carpenter.

Paul Lebenbaum: Relative to the advantages of sector as against round conductors, I know of an instance in which an operating company had a duct line that carried the maximum size of cable using round conductors, the number of ducts being limited by physical conditions. It being necessary to increase the capacity of this line, without resorting to a new route, cables of the sector type, having the same outside diameter as the round type, were substituted for the latter, and the desired increase in capacity was thus obtained.

E. Woodbury: I ask Mr. Nims if a sector cable costs more than the ordinary round type.

H. W. Carpenter: I ask how small size the sector cable is that is used; it occurred to me that if the sizes were carried down too low the corners of conductors would offer considerably greater tendency for electrostatic stresses to break through the insulation there than you would get with the round section.

F. L. Rohrbach: There is one company that I know of which does not recommend making a sector cable in which the conductor is less than $1 / 0$. They claim that conductors smaller than $1 / 0$ are apt to cause too sharp bends or points, which introduce the corona effect and sooner or later cause the cable to break down. This same company recommends an "oval" rather than a "sector" cable, especially for the smaller sizes.

These odd-shaped cables were first introduced for the purpose of saving duct space, and were therefore made in the larger sizes. For example, a $4 / 0$ three-phase 15,000 -volt ordinary cable is as 
large as you can install in a $3 \frac{1}{2}$-inch duct, but by making a "sector" or " oval" cable, you can probably increase the conductor to 350,000 cir. mils. For my part, I can see no reason, but rather an objection, for making a small size cable in these special shapes. My objection would be that you decrease the circumference of the lead sheath, and thus cut down the radiating surface. I think this cable used at Vancouver was made in "sector" shape mainly to hold down the cost of the armor.

M. T. Crawford: I ask Mr. Nims what types of lightning arresters are used on the 12,000-volt lines of the system and what operating success has been secured. On 13,000-volt distributing lines for rural light and power on Puget Sound we have in some cases installed horn gaps without resistance of any kind and set for about three times line voltage. This type of equipment is only installed on the ends of branch feeders into rural districts where it has been necessary to keep the cost of construction down. Electrolytic lightning arresters are invariably used on the busbars in the distributing station. As the 13,000-volt feeders frequently run underneath 55,000 -volt lines for some distance after leaving the station, there is the possibility of accidental contact between circuits, as well as the trouble from lightning to care for. A short circuit on the ends of these light capacity 13,000-volt lines will only trip the circuit breaker and cause a short interruption, which is preferable to damaging distributing transformers. I should like to hear other engineers' ideas on this subject.

F. D. Nims: There is one portion of the paper which apparently I have not made sufficiently clear. At the bottom of page 1302 you will find it stated "Where it is not required to lay more than four cables in a trench, the steel tape cable, laid directly in the ground, will be found to be cheaper than any of the other systems." This does not mean to indicate that I would advocate the use of steel tape cable in all cases. In fact, for more than four cables in a single trench I would probably put in a conduit system of some sort. I have a very vivid recollection of having trouble in a lead of 28 cables running out from a central station and the difficulties we experienced in tracing out the cables.

We find in testing for faults that the number of cables in the trench determines to some extent the accuracy with which we can find that fault. There is one method of testing which we are using at present which has not been mentioned, and that is by the bridge-megger. We find that with this on a $2 / 0$ cable we can locate within about 130 feet. We isolate the section of the cable which is in trouble by means of the section boxes and test from both ends of the faulty piece. By this means we generally run our trouble down to within 75 or 80 feet. If there is a joint in the vicinity or if any digging has been going on we look at that first, but if nothing of this sort occurs we open our trench near where the fault is located and test with 
the "telefault." We find this instrument very good when we can get close to the cable with the exploring coil, but we cannot work it satisfactorily through twenty or thirty inches of earth.

As to repairs where cable is under the pavement; we have very little difficulty with that. After locating it requires a hole possibly three feet square to get down to the cable. The manholes or section boxes are used only for sectionalizing a cable or for cross-connecting cables. Everything is run out from the step-down transformers in rings or loops.

In regard to the street crossings and railroad crossings mentioned here, I will say that labor at the time the job was going on was costing $\$ 3.00$ per 8 -hour day. The duct under railway crossings, under the British Columbia laws, must be in concrete and that runs the cost up considerably. I will state in answer to Prof. Carpenter's question that No. 6 is the smallest conductor we use and very little of that; almost entirely 0 and 00 .

Using city water for transformers costs us for a thousandkilowatt bank of transformers about $\$ 8.00$ per month. We have practically no freezing weather in Vancouver.

I am unable to give any figures on the difference in cost between the sector shape and round conductor cable. At the time we purchased our cable we were unable to obtain a sectorshaped conductor anywhere in the United States or Canada, so bought in England, so that it came into Canada under a preferential tariff. Where we would have to pay full duty from the United States on round conductors, it is difficult to get a line on comparative costs. I believe that the sector-shaped cable is now being manufactured in the United States, but only recently.

As for pole top switches for 60,000 volts, there is very little difficulty in installing them on steel towers, but on our present installation the line is so short that we have had very little occasion to use them. In fact it has been so seldom that we have found it about as easy to open the loop at a strain tower.

Referring to Mr. Crawford's question regarding lightning arresters: Electrolytic arresters are provided on the 12,000-volt lines where they have the station, but in no other place. We run these lines in some instances on the same poles with the 60,000 -volt lines, but do not consider that with good construction there is any probability of accidental contact, and believe that the possibility of such a contact is so remote as not to warrant expensive protection.

In regard to electrolysis I will say that we have had practically no trouble with electrolysis in Vancouver, so that really up there we do not know much about it. We had a good deal of trouble in Mexico City with electrolysis due to the poor bonding on the part of the street railway company, but, as I have mentioned in the paper, we found that the steel tape type of cable stood up very much longer than the straight lead cable placed in a conduit right alongside on the same street, one on each 
side, originally laid by the two different companies which we took over. There was the same electrolytic action, but we pulled out the lead cable about three years before I left there, the steel tape cable remaining, and in those 3 years we had no electrolytic trouble. There was a slight electrolytic action on the armor, but not enough in any way to destroy its effectiveness. What Professor Carpenter said in regard to the strength of the cable we have found in several instances. I know we have had washouts and would have possibly 40 or 50 feet of the cable lying out with no support whatsoever, and would try to get into it with picks, try to hack it with axes, and all sorts of things, and it has been a pretty hard job to get through it.

We built a duct line, that is, going out of the station to the distributing system, at Mexico City. We had a fire some ten years or so ago when I first went there and my first job was to try and straighten out that tangle. When we tried to find out which cable was which it was almost hopeless, so finally while the service was interrupted we built a conduit run to take the cables outside the yard and got rid of the tangle. 